Article

\title{
Analysis of Flood-Vulnerable Areas for Disaster Planning Considering Demographic Changes in South Korea
}

\author{
Hye-Kyoung Lee ${ }^{\circledR}$, Young-Hoon Bae ${ }^{\circledR}$, Jong-Yeong Son $₫$ and Won-Hwa Hong * \\ School of Architectural, Civil, Environmental and Energy Engineering, Kyungpook National University, \\ Daegu 41566, Korea; trot36@hanmail.net (H.L.); byh0105@gmail.com (Y.B.); ssonjy2239@gmail.com (J.S.) \\ * Correspondence: hongwh@knu.ac.kr; Tel.: +82-53-950-5597
}

Received: 15 April 2020; Accepted: 4 June 2020; Published: 9 June 2020

\begin{abstract}
Regional demographic changes are important regional characteristics that need to be considered for the establishment of disaster prevention policies against climate change worldwide. In this study, we propose urban disaster prevention plans based on the classification and characterization of flood vulnerable areas reflecting demographic changes. Data on the property damage, casualties, and flooded area between 2009 and 2018 in 229 municipalities in South Korea were collected and analyzed, and 74 flood vulnerable areas were selected. The demographic change in the selected areas from 2000 to 2018 was examined through comparative analyses of the population size, rate of population change, and population change proportion by age group and gender. Flood vulnerable areas were categorized into three types through K-mean cluster analysis. Based on the analysis results, a strategic plan was proposed to provide information necessary for establishing regional flood-countermeasure policies.
\end{abstract}

Keywords: urban disaster prevention plan; flood vulnerability; climate change; demographic change; cluster analysis

\section{Introduction}

Floods are one of the most dangerous and destructive natural hazards that can cause human loss and economic damages [1-3]. Climate change is expected to increase the frequency of flooding and the extent of damage caused by it [4-6].

To minimize the damage caused by natural hazards, policies, treaties, and conventions, including the Nations Framework Convention on Climate Change (1992), Kyoto Protocol (1997), Hyogo Framework (2005), Sendai Framework (2015) and Paris Agreement (2015), have been established. There is increasing awareness of the important role of policies that consider regional characteristics on the mitigation of damages, adaptation to climate change, and sustainable development in response to climate change [7-11].

Although there are several studies on regional flood risk management globally, policies, practices, and approaches relevant to and effective in some countries may not be applicable to the rest. Indeed, differences in governance structures and processes, topography, weather patterns, and vulnerabilities will lead to difficulties in developing effective community flood risk management strategies [12,13].

Various approaches for establishing a flood disaster prevention plan considering regional characteristics have been proposed, including the development of flood vulnerability assessment indicators and their application for the selection of vulnerable regions.

Cardona et al. [14] calculated the local disaster index using flood damage indicators, such as the number of casualties and victims and the monetary value of the flood damage. Kubal et al. [15] 
proposed three types of area vulnerability indicators: Social indicators, e.g., transport, housing, and commerce; economic indicators, e.g., schools, hospitals, children, and elderly people; and ecological indicators, e.g., forest, biodiversity, and potential pollution. They used these indicators to evaluate the flood vulnerability of a city in Germany by a multicriteria approach. Balica et al. [16] proposed the flood vulnerability index (FVI) with four types of vulnerability indicators: Social, economic, environmental, and physical. Planners and policymakers can use the FVI as a tool to prioritize flood risk hotspots. Balica et al. [17] developed the coastal city FVI using hydro-geological, socio-economical, and politico-administration indicators and applied it to nine coastal cities around the world to evaluate the most vulnerable ones.

In South Korea, various studies on flood damage mitigation have been carried out. The potential flood damage indicator was proposed to evaluate the flood potential by evaluating the possibility of flooding and the flood control capability considering potential damage factors, such as the population, types of property, urbanization rate, and infrastructures, and risk factors, such as flood damage extent, rainfall probability, river improvement rate, and flood control capacity [18]. Regional safety assessment techniques have been proposed to identify the risk of disaster related to natural hazards in specific regions [19]. The flood damage index was developed considering the main causes of flood damage subdivided into natural, social, policy, and facility factors. This index considers 11 causes representing each factor [20]. In areas were divided into risk and vulnerability groups through the excess flood vulnerability index (EFVI) [21].

The results of the flood vulnerability analyses depend on the type, characteristics, and duration of analysis of the selected evaluation indicators, as well as the region under investigation [22-24]. Several studies on flood vulnerability analyses considered flood damage indicators (e.g., casualties and amount of damage), socio-environmental indicators (e.g., urbanization rate, traffic, and residential ratio), regional indicators (coastal area, urban area, and rural area), and population indicators (e.g., the number of people living in the disaster-prone areas, such as coastal areas and areas with a history of multiple floods, disaster-vulnerable population, such as children and the elderly, and the population affected by the disaster).

Demographic change is one of the most important topics discussed globally, along with the issue of climate change $[25,26]$. Demographic change is an important criterion for policymaking because it cannot be reversed in a short time, and it is necessary to analyze its characteristics to use them for policymaking in a pre-emptive manner [27,28]. In its Fifth Assessment Report, the Intergovernmental Panel on Climate Change (IPCC, 2015) highlighted demographic characteristics such as age, gender, income, and health status as parameters to shape the resilience capacities of urban areas [29].

South Korea is the country with the fastest decrease in the birth rate and the fastest growth in an aging population in the world $[30,31]$. Therefore, research has been conducted in various fields on problems and prevention based on demographic changes, and many related national policies have been established. When establishing a disaster prevention policy that prevents human losses and property damage during disasters, it is essential to reflect demographic changes. However, studies discussing and investigating demographic change are scarce in the flood disaster prevention plan. In this study, we propose a strategy for establishing flood disaster preventive urban policies by classifying flood vulnerable areas based on flood characteristics and demographic changes in each region in South Korea.

\section{Materials and Methods}

\subsection{Study Area: Spatial Division and Regional Characteristics of Floods}

South Korea is characterized by its meteorological features: Rainfall during the rainy season between June and September-when air masses from the northern Pacific and tropical cyclones head north-accounts for $55 \%$ of the annual precipitation [32]. In addition, more than two-thirds of the entire land consists of mountainous terrain with weathered rocks, and most of the heavy rainfall is concentrated in the west and south river basin because of the tilted landform (high altitudes in 
the east and low altitudes in the west). Therefore, streams occur frequently in the western region. Further, coastal floods occur repeatedly every year because the three sides of the peninsula are in contact with the sea [33]. However, the recent industrialization and urbanization have resulted in a larger population concentration in metropolitan city areas and increased land use. This has led to an increase in impervious surfaces. Therefore, the frequency and scale of damage caused by urban floods are increasing.

South Korea is divided into 17 administrative regions: Three special cities, six metropolitan cities, and eight provinces (Table 1). There are a total of 69 autonomous districts in nine special cities and metropolitan cities, 78 autonomous cities and 82 counties in nine special cities and metropolitan cities, and eight provinces, making up a total of 229 municipalities, hereinafter referred to as city (si)/county (gun)/district (gu). In this study, we analyzed the flood damage characteristics and the demographic change in the 229 municipalities of si/gun/gu in South Korea.

Table 1. Seventeen administrative regions of South Korea.

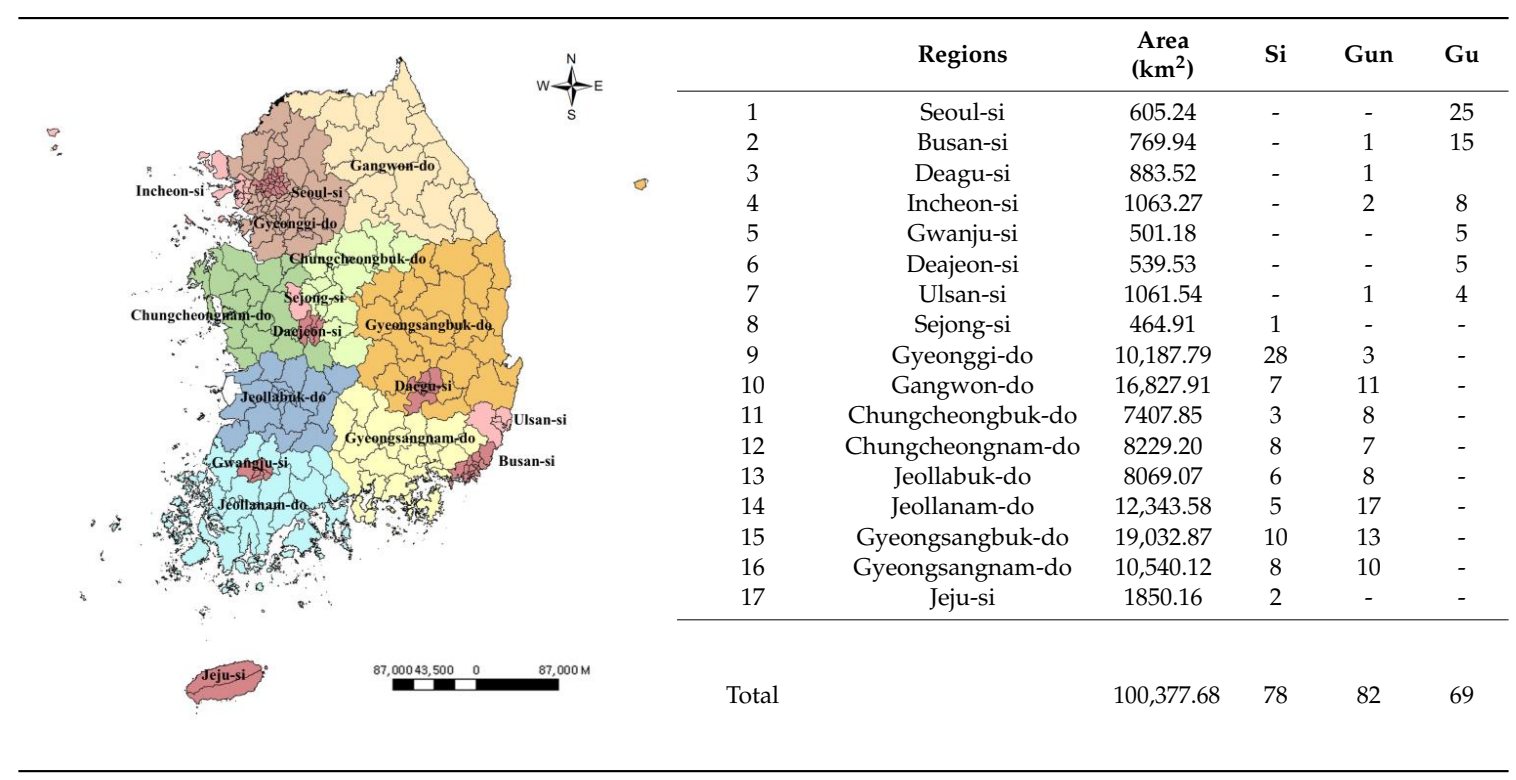

\subsection{Methods}

The purpose of this study is to provide the basis and implications for the establishment of urban disaster preventive policies in response to climate change. To this end, we considered two aspects that were not considered in previous studies. First, in relation to the establishment of a flood disaster prevention policy considering regional characteristics, we conducted regional flood disaster vulnerability assessments of the 229 municipalities in South Korea. In this study, the term "regional flood disaster vulnerability" represents the degree to which flood disaster will occur again based on past flood damage. Second, we categorized the flood vulnerable areas in South Korea by considering the demographic change indicators. In this study, the "Demographic change" implies any change in the population, for example, a change in population size, the rate of population change, and the population proportion change by age groups and gender. The research flow chart applying the two aspects considered is explained below (Figure 1). 


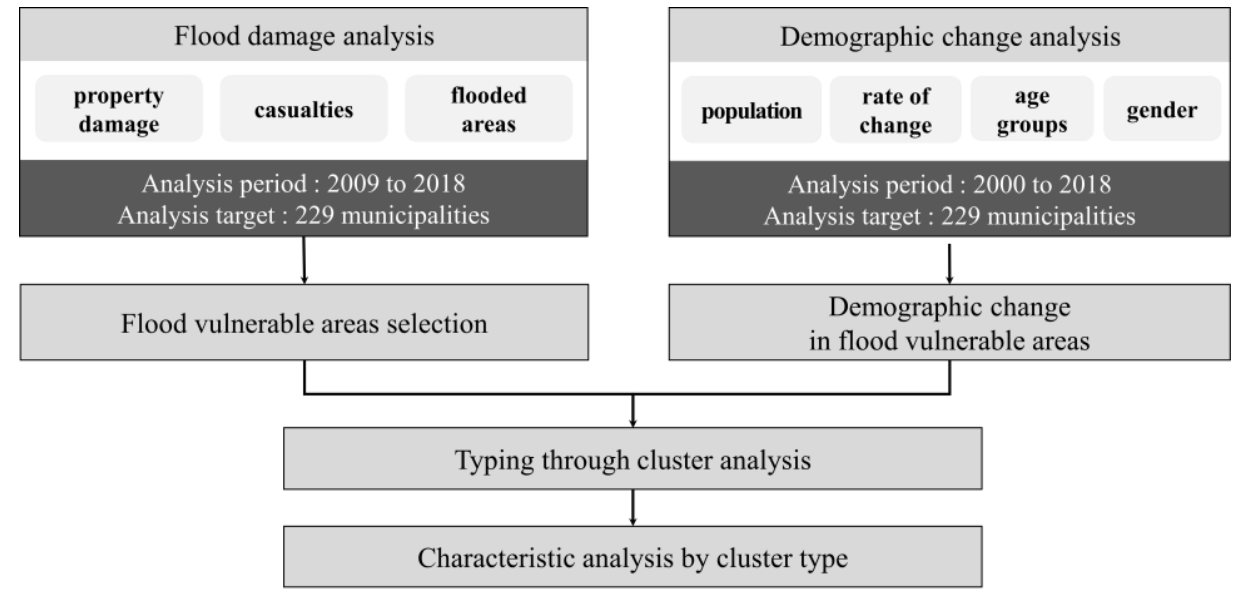

Figure 1. Flow chart of the procedure followed in this study.

First, we analyzed the three types of flood damage characteristics, i.e., the property damage, casualties, and flooded area between 2009 and 2018. We rated the extent of flood damage among the 229 municipalities of si/gun/gu and selected the 30 most flooded areas for each category as the flood vulnerable areas. Second, for the selected flood vulnerable areas, we compared the population size, rate of population change, and population proportion change between 2000 and 2018 and analyzed them by age groups and gender. Third, to generalize the demographic changes in the flood vulnerable areas for comparison, we performed typing through cluster analysis.

In addition, through a comparison of the characteristics by flood vulnerable area type derived from cluster analysis and spatial distribution analysis, this study aims to provide the information necessary to establish flood countermeasure policies for each type of region in the future.

\subsection{Flood Vulnerable Area Selection Data}

Past flood damage data have been widely used for the selection of flood vulnerable areas because they reflect the characteristics and status of the flood damage in each region [34-36]. In particular, flood damage data comprehensively reflect socio-economic and topographical factors. In this study, property damage (one million South Korean won), casualties (persons), and flooded area $\left(\mathrm{km}^{2}\right)$ data were selected as the flood vulnerable area characterization variables.

The South Korean Ministry of the Interior and Safety publishes major statistics on natural hazard damage and recovery status in the annual disasters related to the natural hazard report in Statistics Korea [37]. Statistical data on annual disaster related to the natural hazard report provide statistics for each natural hazard period by facility (public or private facility) and cause (e.g., typhoon, heavy rain, heavy snow, storm, and earthquake). In terms of spatial distribution, they provide the statistics for each major city and province in the 17 administrative regions up to the level of gun/gu. However, the statistics by province are provided according to each natural cause (e.g., heavy rain, typhoon, heavy snow, strong wind, and earthquake), while the statistics in the unit of gun/gu provide only the total of the natural hazard and no classification according to the causes.

In this study, statistical damage data from the flooding of 229 municipalities are extracted by comparing the total number of the natural hazards in the 229 municipalities with the flood damage in the 17 administrative regions and the natural hazard for each period.

The damage status derived for comparative analysis by si/gun/gu was divided into the total area by $\mathrm{si} / \mathrm{gun} / \mathrm{gu}$ to determine the amount of damage per $\mathrm{km}^{2}$, and through comparison, the 30 most damaged regions in each category, i.e., property damage (one million South Korean won $/ \mathrm{km}^{2}$ ), casualties (persons $/ \mathrm{km}^{2}$, and flooded area $\left(\mathrm{km}^{2} / \mathrm{km}^{2}\right)$ were selected as the flood vulnerable areas. 


\subsection{Demographic Change Analysis Data}

Characteristics, such as the population size, distribution, and structure, provide the basic data for policymaking, planning, research, and evaluation. Statistics Korea periodically conducts a population census for all persons in the country. Statistical data for the population census are prepared up to the eup-myeon-dong unit (the sub-district unit of si/gun/gu) and published every five years. However, from 2015, the survey method changed to a registered census method using national administrative data from the total number of surveys, and the data are now published every year [38].

For the analysis of the demographic change in flood vulnerable areas, the total population, population by age, and gender between 2000 and 2018 of the 229 municipalities were extracted from Statistics Korea's population census data. Unlike most demographic analysis studies and the data provided by the National Statistical Office, which categorizes demographic age groups into youth (0-14 years old), working-age (15-64 years old), and aged (+65 years old) [27,39,40], this study further divided the youth group and aged group because they are more vulnerable to the flood damage. In total, five age groups were categorized: Infants (0-9 years old), school-age (10-19 years old), working-age (20-64 years old), aged (65-74 years old), and super-aged (+75). Then, a comparative analysis by $\mathrm{si} / \mathrm{gun} / \mathrm{gu}$ was performed on the population size, rate of population change, population proportion, and proportion change by age group and gender in the last 18 years.

\subsection{Cluster Analysis}

Cluster analysis is a statistical analysis whereby data values are converted into distances based on the similarity between variables, and nearby variables are classified into clusters. This method can be broadly divided into hierarchical clustering and non-hierarchical clustering [41,42]. For the analysis by typing of flood vulnerable areas corresponding to demographic change, this study utilized the K-mean method, which is a non-hierarchical method.

We selected the flood damage characteristics as indicators, i.e., the property damage (million South Korean won $/ \mathrm{km}^{2}$ ), casualties (person $/ \mathrm{km}^{2}$ ), and flooded area $\left(\mathrm{km}^{2} / \mathrm{km}^{2}\right)$, and the demographic change characteristics, i.e., the population by age group and gender (population in 2018), population change (population in 2018-population in 2000), rate of population change ((population in 2018-population in 2000 )/population in $2018 \times 100$ ), proportion (population by age group or gender/total population in $2018 \times 100$ ) and proportion change (proportion in 2018-proportion in 2000) (Table 2).

Table 2. Variables considered for the cluster analysis.

\begin{tabular}{|c|c|c|c|}
\hline \multicolumn{3}{|c|}{ Variable } & Calculation Method \\
\hline \multicolumn{4}{|l|}{ Vulnerable area characteristics } \\
\hline \multicolumn{3}{|c|}{ Property damage (million South Korean won/km²) } & $\begin{array}{l}\text { Flood property damage between } 2009 \\
\text { and } 2018\end{array}$ \\
\hline \multirow{2}{*}{\multicolumn{3}{|c|}{$\begin{array}{l}\left.\text { Casualties (person } / \mathrm{km}^{2}\right) \\
\text { Flooded areas }\left(\mathrm{km}^{2} / \mathrm{km}^{2}\right)\end{array}$}} & Flood casualties 2009 and 2018 \\
\hline & & & Flooded areas between 2009 and 2018 \\
\hline Population change (person) & 10-19 years old & Female & Population in 2018-Population in 2000 \\
\hline Rate of population change (\%) & 20-64 years old & & $\begin{array}{l}\text { (Population in 2018-Population in } \\
\text { 2000)/Population in } 2018 \times 100\end{array}$ \\
\hline Population proportion (\%) & $65-74$ years old & & $\begin{array}{l}\text { Population by age group or } \\
\text { gender/population in } 2018 \times 100\end{array}$ \\
\hline
\end{tabular}




\section{Results}

\subsection{Flood Vulnerable Area Selection}

\subsubsection{Selection and Characteristics of Vulnerable Areas by Major Administrative Region}

Prior to the selection of the detailed flood vulnerable areas among the 229 municipalities of si/gun/gu, based on the annual disaster report of the Ministry of the Interior and Safety, the flood damage of 17 administrative regions nationwide in the last 10 years was recalculated as the ratio of the area, and the results were compared and analyzed (Figure 2).

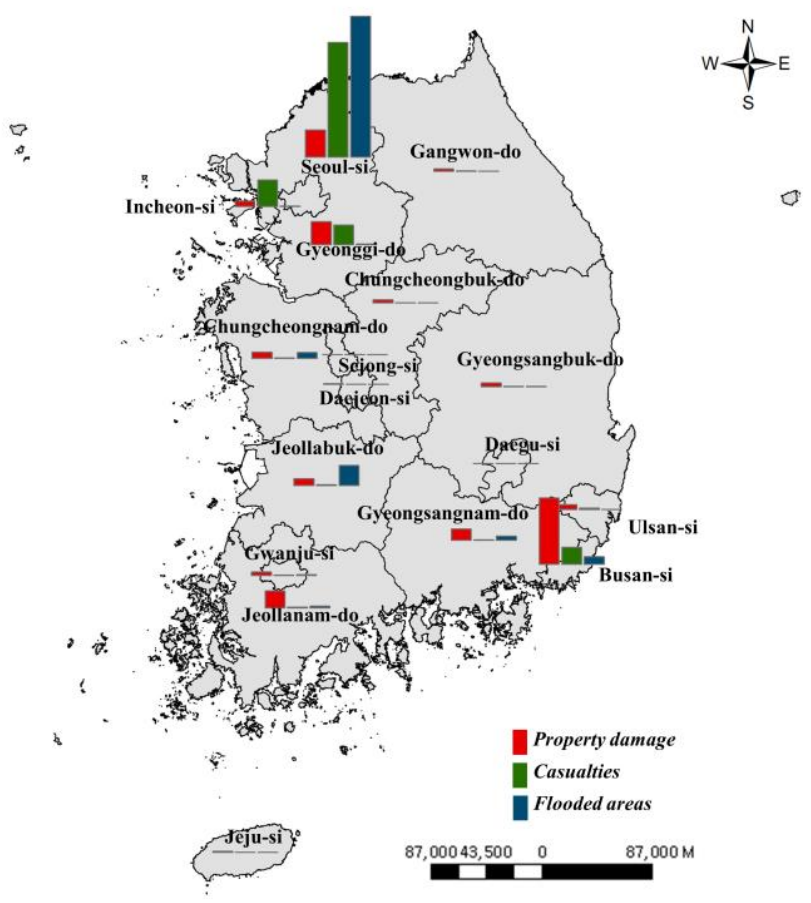

Figure 2. Comparison of flood damage for the 17 administrative regions (2009 to 2018).

As shown in Figure 2, Busan-si was the most damaged with the amount of damage reaching 5077 million won $/ \mathrm{km}^{2}$ (36.45\%), followed by Seoul-si with 2085 million won $/ \mathrm{km}^{2}(14.97 \%)$, and Gyeonggi-do with 1767 million won $/ \mathrm{km}^{2}$ (12.68\%). The casualties were 4632 persons $/ \mathrm{km}^{2}(63.12 \%)$, 1061 persons $/ \mathrm{km}^{2}(14.46 \%)$, and 801 persons $/ \mathrm{km}^{2}(10.91 \%)$ in Seoul-si, Incheon-si, and Gyeonggi-do, respectively. Seoul-si, Jeollabuk-do, and Busan-si had flooded areas of $23.68 \mathrm{~km}^{2} / \mathrm{km}^{2}(77.60 \%)$, $0.38 \mathrm{~km}^{2} / \mathrm{km}^{2}(11.07 \%)$, and $0.14 \mathrm{~km}^{2} / \mathrm{km}^{2}(4.13 \%)$, respectively. Overall, the flood damage in the western provinces was greater than that in the eastern provinces because of the topographical features of the tilted landform (higher altitudes in the east and low altitudes in the west) of South Korea.

In addition, more than half of the property damages, casualties, and flooded areas were observed in two to three administrative regions. A large variation in flood damage was obtained in different regions. These results indicate that flood disaster prevention plans need to be established such that the most damaged regions are prioritized in terms of the implementation of plans. Further, the most damaged areas need to be analyzed with more precise units such as si/gun/gu.

\subsubsection{Selection and Characteristics of Vulnerable Areas (si/gun/gu)}

Considering the last 10 years, the regions were ranked according to the property, casualty, and flood area damages caused by floods in 229 municipalities of si/gun/gu, and the 30 most damaged towns and districts for each category were selected as flood vulnerable areas (Figure 3 and Table 3). 


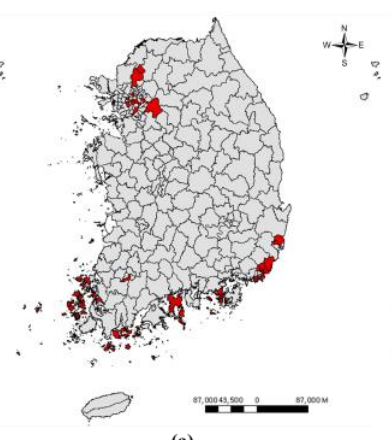

(a)

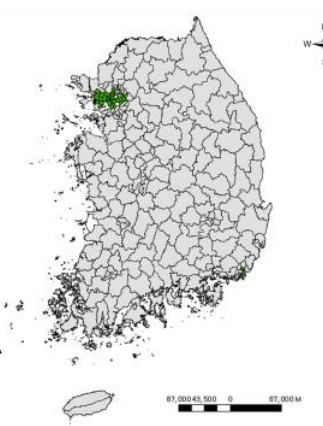

(b)

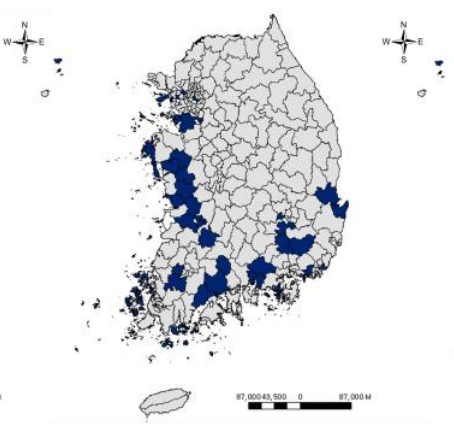

(c)

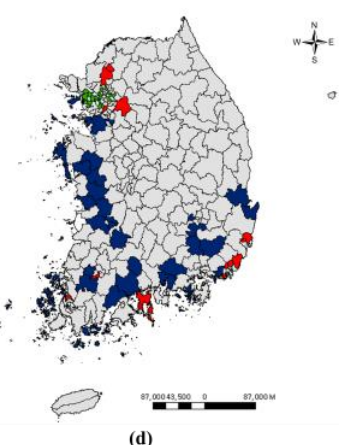

(d)

Figure 3. Spatial analysis of flood vulnerable regions (a) property damage, (b) casualty losses, (c) flooded areas, (d) overlap.

Table 3. Characteristics of regions most vulnerable to floods.; Regions in the two categories of property and casualty(yellow), property and flood area(red), casualty and flood area(green).regions in the three categories of property, casualty, and flood area(gray).

\begin{tabular}{|c|c|c|c|c|c|c|c|c|c|c|c|}
\hline \multicolumn{4}{|c|}{ Property Damage } & \multicolumn{4}{|c|}{ Casualties } & \multicolumn{4}{|c|}{ Flooded Areas } \\
\hline \multicolumn{2}{|c|}{$\begin{array}{l}\text { Municipalities } \\
\text { Si/Do/Gun/Gu }\end{array}$} & \multicolumn{2}{|c|}{$\begin{array}{l}\text { Million } \\
\text { won } / \mathrm{km}^{2}\end{array}$} & \multicolumn{2}{|c|}{$\begin{array}{l}\text { Municipalities } \\
\text { Si/Do/Gun/Gu }\end{array}$} & \multicolumn{2}{|c|}{ Person $/ \mathrm{km} \%$} & \multicolumn{2}{|c|}{$\begin{array}{l}\text { Municipalities } \\
\text { Si/Do/Gun/Gu }\end{array}$} & \multicolumn{2}{|c|}{$\mathrm{km}^{2} / \mathrm{km}^{2} \%$} \\
\hline & \multicolumn{2}{|c|}{$1,392,9.5400 .00$} & \multicolumn{2}{|c|}{ Total } & 7337.55 & 100.00 & \multicolumn{2}{|c|}{ Total } & 3.46 & 100.00 \\
\hline \multicolumn{2}{|c|}{ Sub-Total: Top 30} & \multicolumn{2}{|c|}{$796,5.27 \quad 57.18$} & \multicolumn{2}{|c|}{ Sub-Total: Top 30} & 6440.45 & 87.77 & \multicolumn{2}{|c|}{ Sub-Total: Top 30} & 3.46 & 99.94 \\
\hline Busan & Suyeong & 843.49 & 6.06 & Seoul & Yangcheon & 658.19 & 8.97 & Seoul & Gangseo & 2.683 & 77.59 \\
\hline Busan & Seo & 763.30 & 5.48 & Seoul & Dongjak & 497.73 & 6.78 & Chungcheongbuk & Jeonju & 0.368 & 10.36 \\
\hline Busan & Yeongdo & 702.68 & 5.04 & Seoul & Gwanak & 496.70 & 6.77 & Chungcheongnam & Seocheon & 0.080 & 2.31 \\
\hline Busan & Saha & 555.82 & 3.99 & Incheon & Michuhol & 441.16 & 6.01 & Busan & Yeonje & 0.076 & 2.20 \\
\hline Busan & Nam & 438.00 & 3.14 & Seoul & Gangdong & 364.00 & 4.96 & Busan & Haeundea & 0.066 & 1.91 \\
\hline Seoul & Seocho & 436.77 & 3.14 & Seoul & Guro & 352.38 & 4.80 & Gyeongsangnam & Sacheon & 0.028 & 0.82 \\
\hline Busan & Yeonje & 332.96 & 2.39 & Seoul & Geumcheon & 339.93 & 4.63 & Gyeongsangnam & Changnyeong & 0.028 & 0.81 \\
\hline Busan & Gijang & 316.96 & 2.28 & Seoul & Gwangjin & 314.18 & 4.28 & Jeollanam & Suncheon & 0.024 & 0.68 \\
\hline Seoul & Yangcheon & 299.54 & 2.15 & Incheon & Bupyeong & 313.88 & 4.28 & Gyeonggi & Hwaseong & 0.017 & 0.50 \\
\hline Busan & Buk & 235.70 & 1.69 & Seoul & Seocho & 267.71 & 3.65 & Chungcheongbuk & Gimje & 0.017 & 0.49 \\
\hline Jeollanam & Wando & 228.65 & 1.64 & Seoul & Gangseo & 240.85 & 3.28 & Gyeongsangnam & Miryang & 0.011 & 0.31 \\
\hline Seoul & Gwanak & 228.59 & 1.64 & Gyeonggi & Bucheon & 239.78 & 3.27 & Chungcheongnam & Taean & 0.010 & 0.29 \\
\hline Busan & Dongnae & 227.67 & 1.63 & Gyeonggi & Gwangmyeong & 178.56 & 2.43 & Gwanju & Gwangsan & 0.009 & 0.29 \\
\hline Busan & Haeundea & 226.73 & 1.63 & Busan & Dongnae & 167.68 & 2.29 & Gyeongsangbuk & Pohang & 0.007 & 0.20 \\
\hline Gyeonggi & Dongducheon & 213.61 & 1.53 & Seoul & Gangnam & 162.22 & 2.21 & Chungcheongbuk & Iksan & 0.007 & 0.19 \\
\hline Jeollanam & Mokpo & 191.51 & 1.37 & Seoul & Yeongdeungpo & 145.02 & 1.98 & Chungcheongnam & Cheongyang & 0.006 & 0.18 \\
\hline Busan & Geumjeong & 176.15 & 1.26 & Seoul & Songpa & 119.21 & 1.62 & Gyeongsangnam & Jinju & 0.006 & 0.18 \\
\hline Gwanju & Nam & 149.98 & 1.08 & Seoul & Маро & 115.68 & 1.58 & Chungcheongnam & Buyeo & 0.005 & 0.16 \\
\hline Seoul & Seodaemun & 145.63 & 1.05 & Busan & Yeonje & 112.49 & 1.53 & Jeollanam & Naju & 0.005 & 0.14 \\
\hline Ulsan & Buk & 138.71 & 1.00 & Seoul & Eunpyeong & 106.54 & 1.45 & Jeollanam & Boseong & 0.002 & 0.06 \\
\hline Gyeonggi & Gwangmyeong & 137.73 & 0.99 & Incheon & Namdong & 102.09 & 1.39 & Chungcheongnam & Yesan & 0.002 & 0.06 \\
\hline Gyeonggi & Gwangju & 125.54 & 0.90 & Busan & Nam & 89.21 & 1.22 & Incheon & Jung & 0.002 & 0.06 \\
\hline Gyeonggi & Yangju & 119.23 & 0.86 & Busan & Dong & 87.41 & 1.19 & Jeollanam & Gurye & 0.002 & 0.05 \\
\hline Seoul & Dongjak & 114.73 & 0.82 & Incheon & Gyeyang & 87.37 & 1.19 & Incheon & Bupyeong & 0.001 & 0.04 \\
\hline Ulsan & Jung & 114.17 & 0.82 & Seoul & Dongdaemun & 82.94 & 1.13 & Chungcheongbuk & Imsil & 0.001 & 0.02 \\
\hline Gyeonggi & Uiwang & 111.31 & 0.80 & Seoul & Seodaemun & 80.57 & 1.10 & Incheon & Ongjin & 0.001 & 0.02 \\
\hline Gyeongsangnam & Tongyeong & 99.70 & 0.72 & Seoul & Gangbuk & 72.96 & 0.99 & Deagu & Dalseong & 0.001 & 0.01 \\
\hline Jeollanam & Yeosu & 98.03 & 0.70 & Gyeonggi & Anyang & 70.73 & 0.96 & Busan & Gangseo & 0.000 & 0.01 \\
\hline Seoul & Songpa & 97.71 & 0.70 & Busan & Yeongdo & 68.80 & 0.94 & Chungcheongnam & Hongseong & 0.000 & 0.01 \\
\hline Jeollanam & Shinan & 94.65 & 0.68 & Incheon & Seo & 64.47 & 0.88 & Seoul & Seocho & 0.000 & 0.01 \\
\hline
\end{tabular}

Property damage to the 30 most damaged si/gun/gu accounted for $57.18 \%$ of the total damage. Busan-si Suyeong-gu was the most damaged, accounting for $6.06 \%$ of the total damage. Among the administrative regions analyzed, 12 gu/gun in Busan-si, 6 gu in Seoul-si, 5 si in Gyeonggi-do, and $4 \mathrm{si} /$ gun in Jeollanam-do were the 30 most damaged. Among the administrative regions not categorized into flood vulnerable areas in the analysis, Gwangju-si Nam-gu, Ulsan-si Buk-gu, Ulsan-si Jung-gu, and Gyeongsangnam-do Tongyeong-si were among the 30 most damaged.

The 30 most damaged municipalities accounted for $87.77 \%$ of the total casualties. Yangcheon-gu in Seoul-si had the largest number of casualties, accounting for $8.97 \%$ of the total. The si/gun/gu distribution showed that these 30 areas were in Seoul-si (17 gu), Incheon-si (5 gu/gun), Gyeonggi-do (3 cities), and Busan-si (4 districts).

Gangseo-gu in Seoul-si had the largest damaged area, accounting for $77.59 \%$ of the total damaged area. The flooded areas of the 30 most damaged municipalities accounted for $99.94 \%$ of the total damage. This result indicates that all the regions with flooded areas were ranked in the top 30 . With the analysis of the overlap between the 30 most damaged regions in the three categories of property, casualty, 
and flood area, two si/gun/gu (i.e., Seocho-gu in Seoul-si and Yeonje-gu in Busan-si) overlapped across all three categories of damage, whereas $12 \mathrm{si} / g u n / g u$ (i.e., Seodaemun-gu, Yangcheon-gu, Gangseo-gu, Dongja-gu, Gwanak-gu and Songpa-gu in Seoul-si; Yeongdo-gu, Dongrae-gu, Nam-gu and Haeundae-gu in Busan-si; Bupyeong-gu in Incheon-si; and Gwangmyeong-si in Gyeonggi-do) overlapped across two categories. Considering these, $74 \mathrm{si} / \mathrm{gun} / \mathrm{gu}$ were selected as the final flood vulnerable areas.

\subsection{Demographic Change Analysis}

\subsubsection{Demographic Change across South Korea}

As of 2018, Korea's total population was 51,630,000, which is an increase of $12 \%(5,644,000)$ from that in 2000.). However, the population decreased in 136 out of 229 municipalities (59.39\%) and increased in only 93 regions (40.61\%) (Figure 4). This indicates that, like flood damage, population change has large variations among regions, and this must be considered in disaster preventive urban planning.

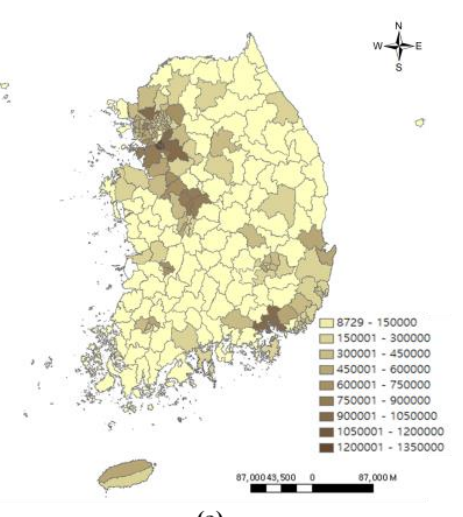

(a)

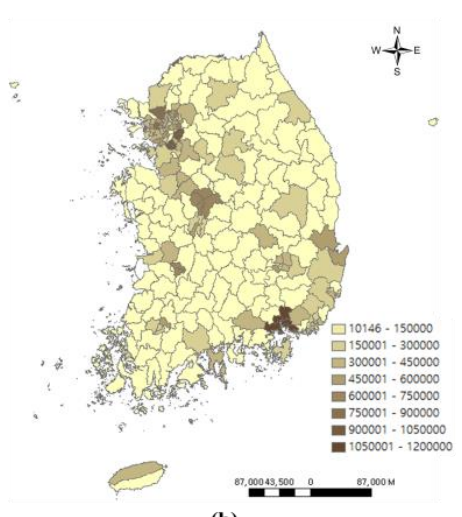

(b)

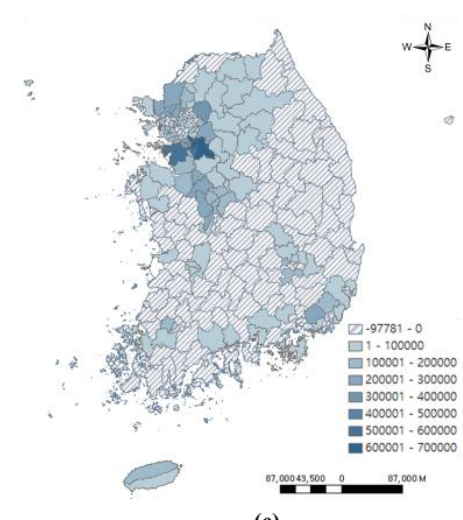

(c)

Figure 4. Spatial analysis of Korea's population change (2000-2018). (a) 2018 population, (b) 2000 population, (c) population change (2018-2000).

Table 4a shows the demographic change for all age groups in South Korea between 2000 and 2018. The super-aged (+75) and infants (0-9) were the age group with the highest increase $(3.96 \%)$ and decrease $(-6.01 \%)$, respectively. The proportion of infants, school-age (10-19), and working-age (20-64) decreased, while that of aged (65-74) and super-aged (+75) increased. Similar to the results of many previous studies, the above findings show that South Korea is the country with the fastest decrease in the birth rate and the fastest aging population in the world. In addition, the low birth rate and fast population aging are expected to accelerate the demographic change in the long run, and the most flood vulnerable group is also changing from the younger groups to the older ones. Based on several analyses, this change is expected to be more severe in the future.

Examining the demographic change by age group and by gender, the proportion of women in the super-aged group (+75) showed the highest increase of 3.97\% in 2018, which represents an increase of $2.38 \%$ compared to the $1.59 \%$ increase in 2000 . The proportion of men in the infants (0-9) group showed the largest decrease to $4.26 \%$ in 2018 , which represents a decrease of $3.30 \%$ over to the $7.55 \%$ increase in 2000. These results indicated that the proportion of women in the flood vulnerability group increased.

\subsubsection{Demographic Change in Flood Vulnerable Areas}

The 74 flood vulnerable areas selected in Section 3.1 account for $17.18 \%\left(17,247 \mathrm{~km}^{2}\right)$ of the total land area in Korea and include 40.29\% (20,799 thousand people) of the total population in 2018. Therefore, most of the vulnerable areas are densely populated. 
Table 4. Demographic changes between 2000 and 2018 in South Korea and in flood vulnerable areas in South Korea.

\begin{tabular}{|c|c|c|c|c|c|c|c|c|c|c|c|c|}
\hline & \multicolumn{6}{|c|}{ (a) South Korea } & \multicolumn{6}{|c|}{ (b) Flood Vulnerable Areas in South Korea } \\
\hline & \multicolumn{3}{|c|}{ Population $\left(\times 10^{3}\right)$} & \multicolumn{3}{|c|}{ Proportion (\%) } & \multicolumn{3}{|c|}{ Population $\left(\times 10^{3}\right)$} & \multicolumn{3}{|c|}{ Proportion (\%) } \\
\hline & 2000 & 2018 & 2018-2000 & 2000 & 2018 & 2018-2000 & 2000 & 2018 & 2018-2000 & 2000 & 2018 & 2018-2000 \\
\hline Total & 45,985 & 51,630 & +5644 & 100.00 & 100.00 & - & 19,255 & 20,799 & +1544 & 100.00 & 100.00 & - \\
\hline Male & 23,068 & 25,877 & +2809 & 50.16 & 50.12 & -0.04 & 9660 & 10,340 & +681 & 50.17 & 49.72 & -0.45 \\
\hline Female & 22,917 & 25,752 & +2835 & 49.84 & 49.88 & +0.04 & 9595 & 10,459 & +864 & 49.83 & 50.28 & +0.45 \\
\hline Infants & 6574 & 4280 & -2294 & 14.30 & 8.29 & -6.01 & 2621 & 1683 & -938 & 13.61 & 8.09 & -5.52 \\
\hline Male & 3473 & 2198 & -1275 & 7.55 & 4.26 & -3.30 & 1383 & 864 & -519 & 7.18 & 4.15 & -3.03 \\
\hline Female & 3102 & 2083 & -1019 & 6.74 & 4.03 & -2.71 & 1238 & 819 & -419 & 6.43 & 3.94 & -2.49 \\
\hline School-age & 6756 & 5036 & -1720 & 14.69 & 9.75 & -4.94 & 2853 & 1943 & -910 & 14.82 & 9.34 & -5.48 \\
\hline Male & 3529 & 2614 & -915 & 7.67 & 5.06 & -2.61 & 1494 & 1005 & -489 & 7.76 & 4.83 & -2.93 \\
\hline Female & 3227 & 2421 & -806 & 7.02 & 4.69 & -2.33 & 1360 & 939 & -421 & 7.06 & 4.51 & -2.55 \\
\hline Working-age & 29,281 & 34,859 & +5577 & 63.68 & 67.52 & +3.84 & 12,536 & 14,215 & +1678 & 65.11 & 68.34 & +3.23 \\
\hline Male & 14,778 & 17,877 & +3099 & 32.14 & 34.63 & +2.49 & 6311 & 7190 & +879 & 32.78 & 34.57 & +1.79 \\
\hline Female & 14,503 & 16,982 & +2478 & 31.54 & 32.89 & +1.35 & 6226 & 7025 & +799 & 32.33 & 33.77 & +1.44 \\
\hline Aged & 2294 & 4202 & +1907 & 4.99 & 8.14 & +3.15 & 853 & 1735 & +883 & 4.43 & 8.34 & +3.92 \\
\hline Male & 942 & 1984 & +1041 & 2.05 & 3.84 & +1.79 & 352 & 821 & +470 & 1.83 & 3.95 & +2.12 \\
\hline Female & 1352 & 2218 & +866 & 2.94 & 4.30 & +1.36 & 501 & 914 & +413 & 2.60 & 4.40 & +1.79 \\
\hline Super-aged & 1078 & 3254 & +2176 & 2.34 & 6.30 & +3.96 & 391 & 1222 & +831 & 2.03 & 5.88 & +3.85 \\
\hline Male & 345 & 1205 & +860 & 0.75 & 2.33 & +1.58 & 120 & 460 & +340 & 0.63 & 2.21 & +1.59 \\
\hline Female & 735 & 2049 & +1316 & 1.59 & 3.97 & +2.38 & 270 & 762 & +492 & 1.40 & 3.66 & +2.26 \\
\hline
\end{tabular}


Table $4 \mathrm{~b}$ also shows the demographic change for all age groups in flood vulnerable areas between 2000 and 2018. Similar to the overall pattern in South Korea, the proportion of aged (65-74) and super-aged (+75) people increased, and the proportion of infants (0-9) and school-age (10-19) people decreased in flood vulnerable areas, indicating a low birth rate and fast population aging. The demographic change according to gender in flood vulnerable areas also showed the largest increase in the proportion of women in the super-aged $(+75)$ groups $(+2.26 \%)$ and the largest decrease in the proportion of men in the infants (0-9) groups $(-3.03 \%)$, similar to the overall pattern in South Korea. Furthermore, the population decreased in 42 regions and increased in 32 regions. The demographic changes by region according to age group are as follows. For infants (0-9) and school-age children (10-19), the population decreased in 67 and 63 regions, respectively, and increased in 7 and 11 regions, respectively, which indicates many regions witnessed a decrease in the population of these age groups. For the working (20-64) and aged (65-74) groups, the population increased in 43 and 63 regions, respectively, and decreased in 31 and 11 regions, respectively. This indicates that many regions demonstrated an increase in the population of these age groups. The super-aged $(+75)$ group demonstrated a population increase in all 74 vulnerable areas.

\subsection{Characteristics of Flood Vulnerable Area Type Reflecting Demographic Change}

\subsubsection{Type Classification through Cluster Analysis}

For the analysis of flood vulnerable area type reflecting demographic changes, a K-mean cluster analysis was conducted by selecting flood vulnerability and demographic change characteristics as variables. Unlike hierarchical cluster analyses, the K-mean cluster analysis requires the number of clusters to be specified in advance. To select the appropriate number of clusters, the number of clusters was varied, and the number of cases for each cluster was determined through ten iterations (Table 5). In this process, it was confirmed that each case $(18,25,30,1)$ showed relatively uniform distribution when classified into four clusters, and, excluding one region with exceptional characteristics, $73 \mathrm{si} / \mathrm{gun} / \mathrm{gu}$ were categorized into three types.

Table 5. Comparison of the number of cases by clusters.

\begin{tabular}{ccccccc}
\hline \multirow{2}{*}{ Cluster } & \multicolumn{7}{c}{ Number of Cases in Each Cluster } \\
\cline { 2 - 7 } & $\mathbf{1}$ & $\mathbf{2}$ & $\mathbf{3}$ & $\mathbf{4}$ & $\mathbf{5}$ & $\mathbf{6}$ \\
\hline 2 & 30 & 44 & & & & \\
3 & 35 & 38 & 1 & & & \\
4 & 18 & 25 & 30 & 1 & 1 & \\
5 & 11 & 12 & 21 & 29 & 22 & 1 \\
6 & 18 & 2 & 18 & 21 & & \\
\hline
\end{tabular}

\subsubsection{Analysis of Characteristics by Type}

The characteristics of three types of flood vulnerable areas derived through cluster analysis were examined by comparing the mean values of the flood vulnerable area characteristic variables and demographic change characteristic variables (Table 6).

Regions in Cluster 1 (Type 1) have the smallest property damage due to floods but the largest casualties and flooded areas, and includes $18 \mathrm{si} / \mathrm{gun} / \mathrm{gu}$, with Yangcheon-gu, Seoul-si, which has the largest number of casualties, and Dongjak-gu, Gwanak-gu in Seoul-si, Haeundae-gu in Busan-si, Anyang-si in Gyeonggi-do, and Pohang-si in Gyeongsangbuk-do (Table 7). In addition, Type 1 regions have the largest mean population and relatively large population growth (smaller than that of Type 3 regions). Although the male population in Type 1 regions increased by 4273 thousand people on average, the female population increased by 13,851 thousand people, indicating a significant increase in the female population. The decrease in the infants (0-9) and school-age (10-19) population and the 
increase in the working-age (20-64), aged (65-74), super-aged (+75) population is characteristic of the pattern of South Korea, i.e., low birth rate and fast population aging.

Table 6. Characteristics of clusters and comparison of the variables' mean values.

\begin{tabular}{|c|c|c|c|c|c|c|}
\hline Variable & \multicolumn{2}{|c|}{ Cluster 1} & \multicolumn{2}{|c|}{ Cluster 2} & \multicolumn{2}{|c|}{ Cluster 3} \\
\hline Property damage & \multicolumn{2}{|c|}{94.50 million won $/ \mathrm{km}^{2}$} & \multicolumn{2}{|c|}{112.43 million won $/ \mathrm{km}^{2}$} & \multicolumn{2}{|c|}{173.53 million won $/ \mathrm{km}^{2}$} \\
\hline Casualties & \multirow{2}{*}{\multicolumn{2}{|c|}{$\begin{array}{c}241.09 \text { person } / \mathrm{km}^{2} \\
0.17 \mathrm{~km}^{2} / \mathrm{km}^{2}\end{array}$}} & \multirow{2}{*}{\multicolumn{2}{|c|}{$\begin{array}{c}10.24 \text { person } / \mathrm{km}^{2} \\
0.01 \mathrm{~km}^{2} / \mathrm{km}^{2}\end{array}$}} & \multirow{2}{*}{\multicolumn{2}{|c|}{$\begin{array}{c}71.83 \text { person } / \mathrm{km}^{2} \\
0.00 \mathrm{~km}^{2} / \mathrm{km}^{2}\end{array}$}} \\
\hline \multirow[t]{2}{*}{ Flooded area } & & & & & & \\
\hline & Male & Female & Male & Female & Male & Female \\
\hline Population $\left(\times 10^{3}\right)$ & 253,366 & 259,782 & 40,145 & 39,388 & 145,500 & 147,723 \\
\hline Infants & 20,284 & 19,209 & 2998 & 2847 & 12,420 & 11,775 \\
\hline School-age & 24,313 & 22,593 & 3454 & 3166 & 14,590 & 13,706 \\
\hline Working-age & 178,617 & 179,774 & 26,298 & 22,947 & 100,926 & 99,145 \\
\hline Aged & 19,866 & 21,822 & 4305 & 4849 & 11,280 & 12,717 \\
\hline Super-aged & 10,285 & 16,385 & 3088 & 5578 & 6283 & 10,380 \\
\hline Population change $\left(\times 10^{3}\right)$ & 4273 & 13,851 & -478 & -2088 & 10,025 & 13,011 \\
\hline Infants & $-15,278$ & $-12,679$ & -1924 & -1571 & -7734 & -6231 \\
\hline School-age & $-14,940$ & $-12,943$ & -2447 & -2173 & -6325 & -5457 \\
\hline Working-age & 14,109 & 17,266 & 693 & -1974 & 12,670 & 11,683 \\
\hline Aged & 12,584 & 11,532 & 1,250 & 402 & 6643 & 6139 \\
\hline Super-aged & 7803 & 10,680 & 1953 & 3230 & 4773 & 6879 \\
\hline \multicolumn{7}{|l|}{ Rate of population change } \\
\hline Infants & $-77.55 \%$ & $-67.95 \%$ & $-101.40 \%$ & $-91.73 \%$ & $-71.65 \%$ & $-61.23 \%$ \\
\hline School-age & $-65.15 \%$ & $-60.77 \%$ & $-86.37 \%$ & $-88.36 \%$ & $-50.66 \%$ & $-46.68 \%$ \\
\hline Working-age & $+6.71 \%$ & $+8.63 \%$ & $-3.44 \%$ & $-18.70 \%$ & $+11.29 \%$ & $+11.24 \%$ \\
\hline Aged & $+63.06 \%$ & $+52.87 \%$ & $+25.03 \%$ & $+2.80 \%$ & $+59.51 \%$ & $+48.62 \%$ \\
\hline Super-aged & $+75.79 \%$ & $+64.71 \%$ & $+62.93 \%$ & $+57.80 \%$ & $+76.28 \%$ & $+66.91 \%$ \\
\hline Population proportion & $49.37 \%$ & $50.63 \%$ & $50.48 \%$ & $49.52 \%$ & $49.62 \%$ & $50.38 \%$ \\
\hline Infants & $3.95 \%$ & $3.74 \%$ & $3.77 \%$ & $3.58 \%$ & $4.24 \%$ & $4.02 \%$ \\
\hline School-age & $4.74 \%$ & $4.40 \%$ & $4.34 \%$ & $3.98 \%$ & $4.98 \%$ & $4.67 \%$ \\
\hline Working-age & $34.81 \%$ & $35.03 \%$ & $33.07 \%$ & $28.85 \%$ & $34.42 \%$ & $33.81 \%$ \\
\hline Aged & $3.87 \%$ & $4.25 \%$ & $5.41 \%$ & $6.10 \%$ & $3.85 \%$ & $4.34 \%$ \\
\hline Super-aged & $2.00 \%$ & $3.19 \%$ & $3.88 \%$ & $7.01 \%$ & $2.14 \%$ & $3.54 \%$ \\
\hline \multicolumn{7}{|l|}{$\begin{array}{l}\text { Rate of population } \\
\text { proportion change }\end{array}$} \\
\hline Infants & $-3.23 \%$ & $-2.70 \%$ & $-2.23 \%$ & $-1.80 \%$ & $-3.22 \%$ & $-2.65 \%$ \\
\hline School-age & $-3.19 \%$ & $-2.78 \%$ & $-2.84 \%$ & $-2.52 \%$ & $-2.77 \%$ & $-2.42 \%$ \\
\hline Working-age & $+1.58 \%$ & $+2.21 \%$ & $+1.88 \%$ & $-1.50 \%$ & $+1.75 \%$ & $+1.44 \%$ \\
\hline Aged & $+2.40 \%$ & $+2.17 \%$ & $+1.69 \%$ & $+0.68 \%$ & $+2.13 \%$ & $+1.90 \%$ \\
\hline Super-aged & $+1.50 \%$ & $+2.04 \%$ & $+2.50 \%$ & $+4.15 \%$ & $+1.58 \%$ & $+2.24 \%$ \\
\hline
\end{tabular}

Type 2 regions cover 25 si/gun/gu, including Seo-gu and Dong-gu in Busan-si, Jung-gu and Ongjin-gun in Incheon-si, Dongducheon-si, and Uiwang-si in Gyeonggi-do, Buyeo-gun and Seocheon-si in Chungcheongnam-do Kim Jae-gun, Insil-gun in Chungcheongbuk-do, Naju-si, and Gurye-gun in Jeollanam-do and Tongyeong-si and Sacheon-si in Gyeongsangnam-do (Table 7). Excluding four gu in Busan-si and two gu/gun in Incheon-si, the majority of the Type 2 regions are regional small- or medium-sized cities with the smallest population sizes and are the only ones where the populations decreased. In the Type 2 regions, the population decreased across a wide range of ages from infants (0-9) to working-age (20-64), and the rate of decrease was greater than that in Type 1 and three regions. The working-age (20-64) female population $(-18.70 \%)$ and the infants $(0-9)$ male population $(-101.40 \%)$ decreased sharply. The proportion of infants and school-age people was the smallest, and that of aged and super-aged was the highest, which had the greatest contribution to the low birth rate and fast population aging. In addition, the casualties due to floods were the fewest among the three types, and the property damages and flooded areas were the second largest, which is attributed to the larger average land area of Type 2 flooded areas. 
Type 3 regions have the largest property damage owing to floods and include 30 si/gun/gu. Among these, Suyeong-gu in Busan-si, Gwangjin-gu, and Dongdaemun-gu in Seoul-si, Dalseong-gun in Daegu-si, Gyeyang-gu in Incheon-si, Nam-gu in Gwangju-si, and Jung-gu in Ulsan-si have the greatest property damage (Table 7). The population size in Type 3 regions is smaller than that in Type 1 regions, but the population growth is the largest. The number of men and women increased uniformly, and the growth rate of working-age (20-64) (male: $11.29 \%$, female: $11.24 \%$ ) is large. In addition, the reduction rate of infants (0-9) is the smallest, and the population proportion is the largest.

Table 7. Regional classification by type.

\begin{tabular}{|c|c|c|}
\hline Cluster (number) & Characteristics & Regions (Si/Do/Gun/Gu) \\
\hline $\begin{array}{c}2 \\
(25)\end{array}$ & $\begin{array}{l}\text { Small and medium cities; } \\
\text { population reduction; } \\
\text { low birth rate; fast } \\
\text { population aging }\end{array}$ & $\begin{array}{l}\text { Busan: Seo, Dong, Yeongdo, and Gangseo; Incheon: Jung and Ongjin; } \\
\text { Gyeonggi: Dongducheon and Uiwang; Chungcheongnam: Buyeo, } \\
\text { Seocheon, Cheongyang, Hongseong, Yesan, and Taean; Chungcheongbuk: } \\
\text { Gimje and Imsil; Jeollanam: Naju, Gurye, Boseong, Wando, and Shinan; } \\
\text { Gyeongsangnam: Tongyeong, Sacheon, Miryang, and Changnyeong }\end{array}$ \\
\hline $\begin{array}{c}3 \\
(30)\end{array}$ & $\begin{array}{l}\text { Large property damage; } \\
\text { high population growth; } \\
\text { high proportion of young } \\
\text { people }\end{array}$ & $\begin{array}{l}\text { Seoul: Gwangjin, Dongdaemun, Gangbuk, Seodaemun, Mapo, Geumcheon, } \\
\text { and Seocho; Busan: Dongnae, Nam, Buk, Saha, Geumjeong, Yeonje, } \\
\text { Suyeong, and Gijang; Deagu: Dalseong;, Incheon: Gyeyang and Seo; } \\
\text { Gwanju: Nam and Gwangsan; Ulsan: Jung and Buk; Gyeonggi: } \\
\text { Gwangmyeong, Gwangju, and Yangju; Chungcheongbuk: Iksan; Jeollanam: } \\
\text { Mokpo, Yeosu, and Suncheon; Gyeongsangnam: Jinju }\end{array}$ \\
\hline
\end{tabular}

\subsection{Recommendations}

Flood disaster risk reduction management is a continuous process that involves identifying issues, defining objectives, assessing risks, appraising strategies, implementation, monitoring, and review [43]. Flood damage and demographic characteristics are constantly changing, and there is a need to monitor the changing trends and re-evaluate flood vulnerable areas. Further, the effectiveness of the proposed strategy for each region needs to be monitored based on type, and the goals and strategies need to be adjusted according to the monitoring results. Within this monitoring system, evaluating flood vulnerable areas is considered a cyclical process involving the design and evaluation of alternative strategies. The proposed monitoring system is illustrated in Figure 5 and explained below:

1. Data monitoring: Identify trends of change through flood damage and population census data monitoring.

2. Flood vulnerable area monitoring: The flood vulnerable areas are re-selected and re-categorized according to the changing trend.

3. Strategic planning monitoring: The regional type is divided into "existing" and "new" to monitor the strategic plan by region type.

4. Strategic effectiveness monitoring: The strategy is adjusted by monitoring the effectiveness of the strategy in a region, or by reviewing the application of other strategies in other regions where they worked well. 


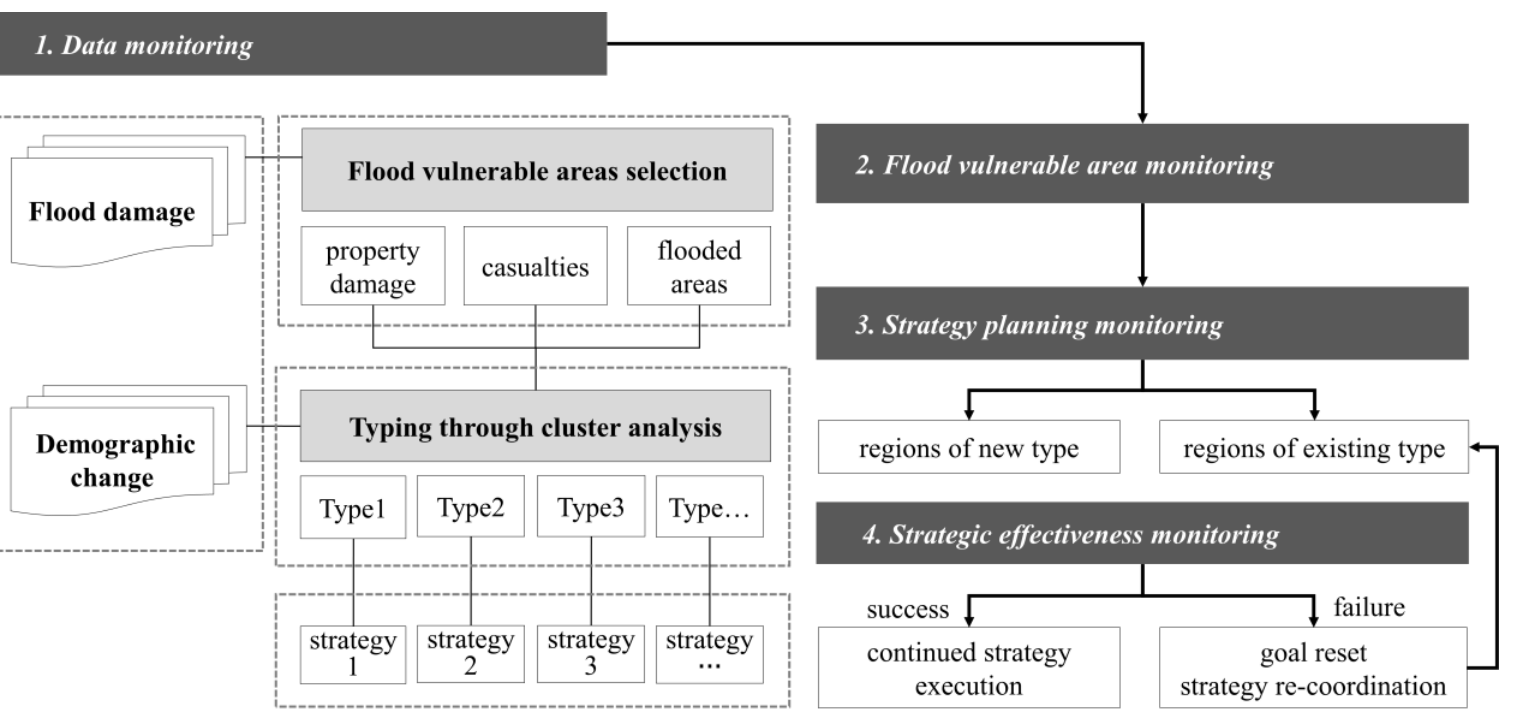

Figure 5. Monitoring flood risk prevention strategies.

\section{Discussions and Conclusions}

In this study, we designed a methodology for categorizing flood-vulnerable areas through cross and cluster analyses of flood damage and demographic changes. The methodology was applied to 229 local governments in South Korea to derive three types of flood-vulnerable areas.

Type 1 regions comprise of 18 municipalities (si/gun/gu) with metropolitan cities having a large average population (4865 people $/ \mathrm{km}^{2}$ ). The total population has increased since 2000. In particular, the female population in these areas has increased significantly compared to the male population, and floods have caused substantial human casualties.

Type 2 areas typically include small- and medium-sized regional cities with a small population over a large area (209 people $/ \mathrm{km}^{2}$ ). Korea has 25 Type 2 municipalities (si/gun/gu). The flood damage in these regions is not as extensive as that in other areas, however, they are the only regions characterized by population decrease, low birth rate, and aging population.

Type 3 areas include 30 Korean municipalities (si/gun/gu) with a population size (1716 people $/ \mathrm{km}^{2}$ ) larger than the overall average population size of Korea (514 people $\left./ \mathrm{km}^{2}\right)$, but smaller than the metropolitan Type 1 . This is a new city type with large population growth and the largest increase in the youth population.

The vulnerable areas of categorized floods should be handled at the community level through various strategies, such as installing structures that increase height (e.g., levees and sandbags [44,45]), acquiring open spaces and conserving wetlands [46-49], land use planning for further development and densification regulation in flood-prone areas [50], flood-proofing buildings [51], insurance programs and tax incentives for flood risk [52-54], flood risk response strategy communication (e.g., flood information, early disaster warning, risk mapping and distribution, and evacuation training [50,55]), involvement of local community members in the flood planning and recovery processes $[49,50]$, minimization of the constraints of the disaster vulnerable population $[49,56]$ and mitigation efforts for flood risk factors through continuous monitoring of the local community [49,50]. The strategy presented in this paper can be additionally considered when establishing flood prevention measures on the local community level. Therefore, the proposed strategy cannot encompass all elements of community flood disaster prevention planning. A flood risk prevention strategy appropriate to the area type can be developed through additional research. Moreover, the suitability of the proposed strategy should be verified through continuous monitoring.

This study differs from previous studies in that it categorized flood-vulnerable areas into three types considering the demographic change factors and improved the accuracy of the regional differences by subdividing Korea into 229 municipalities and performing a detailed analysis. However, as suggested 
in Section 3.4, flood damage and demographic factors are constantly changing variables. Therefore, flood-vulnerable areas must be re-evaluated through monitoring and continuous improvement and update of response measures and planning. In addition, in terms of demographic change, the quality of research is expected to be further improved if various disaster vulnerable group variables, such as foreigners, the disabled, and the poor, can be additionally considered and if long-term demographic data are supplemented.

Author Contributions: Conceptualization, H.-K.L.; Methodology, H.-K.L.; Writing—original draft, H.-K.L.; Writing - review and editing, Y.-H.B. and J.-Y.S.; Visualization, Y.-H.B. and J.-Y.S.; Supervision, W.-H.H. All authors have read and agreed to the published version of the manuscript.

Funding: This research was funded by NATIONAL RESEARCH FOUNDATION OF KOREA (NRF), funded by the government of Korea (MSIT), grant number 2019R1A2C3002219.

Conflicts of Interest: The authors declare no conflict of interest.

\section{References}

1. Wisner, B.; Blaikie, P.; Cannon, T.; Davis, I. At Risk; Taylor \& Francis: Abingdon, UK, 1994; ISBN 978-0-203-44423-8.

2. Jonkman, S.N. Global Perspectives on loss of human life caused by floods. Nat. Hazards 2005, 34, 151-175. [CrossRef]

3. Douben, K.-J. Characteristics of river floods and flooding: A global overview, 1985-2003. Irrig. Drain. 2006, 55, S9-S21. [CrossRef]

4. Botzen, W.; Van den Bergh, J.C.J.M.; Bouwer, L.M. Climate change and increased risk for the insurance sector: A global perspective and an assessment for the Netherlands. Nat. Hazards 2009, 52, 577-598. [CrossRef]

5. Kvočka, D.; Falconer, R.A.; Bray, M. Flood hazard assessment for extreme flood events. Nat. Hazards 2016, 84, 1569-1599. [CrossRef]

6. Diffenbaugh, N.; Singh, D.; Mankin, J.S.; Horton, D.E.; Swain, D.L.; Touma, D.; Charland, A.; Liu, Y.; Haugen, M.; Tsiang, M.; et al. Quantifying the influence of global warming on unprecedented extreme climate events. Proc. Natl. Acad. Sci. USA 2017, 114, 4881-4886. [CrossRef]

7. Davoudi, S.; Crawford, J.; Mehmood, A. Planning for Climate Change: Strategies for Mitigation and Adaptation for Spatial Planners; Routledge: London, UK, 2009; ISBN 9781849770156. [CrossRef]

8. Biesbroek, R.; Swart, R.; Van Der Knaap, W.G. The mitigation-adaptation dichotomy and the role of spatial planning. Habitat Int. 2009, 33, 230-237. [CrossRef]

9. Kim, Y.J.; Lee, J.E.; Kim, K.B. Development of flood mitigation strategies for urban resilience-focused on the assessment of gulpo stream's watershed in Incheon, South Korea. Urban Des. Inst. Korea 2018, 19, 5-20. [CrossRef]

10. Pielke, R.A.; Downton, M.W. Precipitation and damaging floods: Trends in the United States, 1932-1997. J. Clim. 2000, 13, 3625-3637. [CrossRef]

11. Brody, S.D.; Kang, J.E.; Bernhardt, S. Identifying factors influencing flood mitigation at the local level in Texas and Florida: The role of organizational capacity. Nat. Hazards 2009, 52, 167-184. [CrossRef]

12. Laurien, F.; Hochrainer-Stigler, S.; Keating, A.; Campbell, K.; Mechler, R.; Czajkowski, J. A typology of community flood resilience. Reg. Environ. Chang. 2020, 20,1-14. [CrossRef]

13. Jongman, B.; Winsemius, H.C.; Fraser, S.A.; Muis, S.; Ward, P.J. Assessment and adaptation to climate change-related flood risks. In Oxford Research Encyclopedia of Natural Hazard Science; Oxford University Press: Oxford, UK, 2018. [CrossRef]

14. Cardona, O.D. Indicators of disaster risk and risk management. Science 2005, 284, 939-942. [CrossRef]

15. Kubal, C.; Haase, D.; Meyer, V.; Scheuer, S. Integrated urban flood risk assessment-adapting a multicriteria approach to a city. Nat. Hazards Earth Syst. Sci. 2009, 9, 1881-1895. [CrossRef]

16. Balica, S.F.; Douben, N.; Wright, N. Flood vulnerability indices at varying spatial scales. Water Sci. Technol. 2009, 60, 2571-2580. [CrossRef]

17. Balica, S.F.; Wright, N.; van Der Meulen, F. A flood vulnerability index for coastal cities and its use in assessing climate change impacts. Nat. Hazards 2012, 64, 73-105. [CrossRef] 
18. Ministry of Land, Infrastructure and Transport. Comprehensive Water Resources Plan-Water Vision 2020; Ministry of Land, Infrastructure and Transport: 2000. Available online: http://molit.go.kr (accessed on 5 March 2020).

19. National Disaster Management Research Institute. Development of Evaluation and Diagnosis Methods of Safer City; National Disaster Management Research Institute: 2013. Available online: http://ndmi.go.kr (accessed on 5 March 2020).

20. Park, T.S.; Kim, K.M.; Yun, Y.S.; Lee, S.B. Analysis of Flood Damage Characteristics and Development of Flood Damage Index; Korea Research Institute for Human Settlements: Daejeon, Korea, 2005; Available online: https://scholar.google.co.kr/scholar?hl=ko\&as_sdt=0\%2C5\&q=Analysis+of+flood+ damage+characteristics+and+development+of+flood+damage+index\&btnG (accessed on 5 March 2020).

21. Korea Agency for Infrastructure Technology Advancement. Development of Evaluation Technique on the Abnormal Flood; Korea Agency for Infrastructure Technology Advancement: 2008. pp. 1-202. Available online: https://www.kaia.re.kr (accessed on 5 March 2020).

22. Alkema, D. Flood risk assessment for EIA: An example of a motorway near Trento, Italy. Stud. Trentini Di Sci. Nat. Acta Geol. 2003, 78, 147-153.

23. Tingsanchali, T.; Karim, M.F. Flood hazard and risk analysis in the southwest region of Bangladesh. Hydrol. Process. 2005, 19, 2055-2069. [CrossRef]

24. Dang, N.M.; Babel, M.S.; Luong, H.T. Evaluation of food risk parameters in the day river flood diversion area, red river delta, vietnam. Nat. Hazards 2010, 56, 169-194. [CrossRef]

25. Rauscher, M. Demographic change and climate change. Environ. Dev. Econ. 2019, 25, 5-20. [CrossRef]

26. Raker, E.J. Natural hazards, disasters, and demographic change: The case of severe tornadoes in the United States, 1980-2010. Demography 2020, 57, 653-674. [CrossRef]

27. Liddle, B.; Lung, S.; Liddle, B. Age-structure, urbanization, and climate change in developed countries: Revisiting STIRPAT for disaggregated population and consumption-related environmental impacts. Popul. Environ. 2010, 31, 317-343. [CrossRef]

28. Donner, W.; Rodriguez, H. Population composition, migration and inequality: The Influence of demographic changes on disaster risk and vulnerability. Soc. Forces 2008, 87, 1089-1114. [CrossRef]

29. Oriangi, G.; Albrecht, F.; Di Baldassarre, G.; Bamutaze, Y.; Mukwaya, P.I.; Ardö, J.; Pilesjö, P. Household resilience to climate change hazards in Uganda. Int. J. Clim. Chang. Strat. Manag. 2020, 12, 59-73. [CrossRef]

30. Kim, E.J.; Kim, M.-Y.; Kim, H. Spatio-temporal trend of aging regions and their neighborhood environment: Findings from daegu metropolitan City, Korea. Sustainability 2020, 12, 1218. [CrossRef]

31. Park, E.H. Ultra-low fertility and policy response in South Korea: Lessons from the case of Japan. Ageing Int. 2020, 45, 191-205. [CrossRef]

32. Han River Flood Control Office. Characteristics of Flooding in Korea. Available online: http://www.hrfco.go. $\mathrm{kr} /$ web/floodPage/floodClass.do (accessed on 5 March 2020).

33. Lee, J.S.; Myeong, S.; Choi, H.I.; Korea Environment Institute; Yeungnam University. Development of a flood vulnerability assessment methodology for coastal areas. J. Korean Soc. Hazard Mitig. 2017, 17, 397-402. [CrossRef]

34. Messner, F.; Meyer, V. Flood damage, vulnerability and risk perception-Challenges for flood damage research. In Flood Risk Management: Hazards, Vulnerability and Mitigation Measures; Springer: Dordrecht, Netherlands, 2007; pp. 149-167.

35. Scheuer, S.; Haase, D.; Meyer, V. Exploring multicriteria flood vulnerability by integrating economic, social and ecological dimensions of flood risk and coping capacity: From a starting point view towards an end point view of vulnerability. Nat. Hazards 2010, 58, 731-751. [CrossRef]

36. Kim, J.K.; Park, I.C.; Yang, D.M. The development of a disaster situation analysis system based on national disaster statistics and damage information-A case of heavy rains and typhoons in South Korea. Crisis Emerg. Manag. Theory Prax. 2020, 16, 175-183. [CrossRef]

37. The Ministry of the Interior and Safety (MOIS). Statistical Yearbook of Natural Disaster. Available online: http://kosis.kr/statHtml/statHtml.do?orgId=110\&tblId=DT_15603N_004\&conn_path=I2 (accessed on 5 March 2020).

38. Statistics Korea. Census. Available online: http://kosis.kr/statHtml/statHtml.do?orgId=101\&tblId=DT_ 1IN1503\&conn_path=I3 (accessed on 5 March 2020). 
39. Barbieri, A.F.; Domingues, E.; Queiroz, B.L.; Ruiz, R.M.; Rigotti, J.I.; Carvalho, J.A.M.; Resende, M.F. Climate change and population migration in Brazil's Northeast: Scenarios for 2025-2050. Popul. Environ. 2010, 31, 344-370. [CrossRef]

40. Grosso, N.; Dias, L.; Costa, H.P.; Santos, F.D.; Garrett, P. Continental portuguese territory flood social susceptibility index. Nat. Hazards Earth Syst. Sci. 2015, 15, 1921-1931. [CrossRef]

41. Rao, M.R. Cluster analysis and mathematical programming. J. Am. Stat. Assoc. 1971, 66, 622-626. [CrossRef]

42. Hennig, C.; Meila, M.; Murtagh, F.; Rocci, R. Handbook of Cluster Analysis; Chapman and Hall/CRC: New York, NY, USA, 2015; ISBN 9781466551893. [CrossRef]

43. Tasseff, B.; Bent, R.W.; Van Hentenryck, P. Optimization of structural flood mitigation strategies. Water Resour. Res. 2019, 55, 1490-1509. [CrossRef]

44. Tasseff, B.; Bent, R.; van Hentenryck, P. Optimal flood mitigation over flood propagation approximations. In Lecture Notes in Computer Science (Including Subseries Lecture Notes in Artificial Intelligence and Lecture Notes in Bioinformatics); Springer: Cham, Switzerland, 2016; pp. 358-373.

45. Judi, D.; Tasseff, B.; Bent, R.; Pan, F. Topography-based Flood Planning and Optimization Capability Development Report; Los Alamos National Laboratory: Los Alamos, NM, USA, 2014. [CrossRef]

46. Brody, S.D.; Highfield, W.E. Open space protection and flood mitigation: A national study. Land Use Policy 2013, 32, 89-95. [CrossRef]

47. Brody, S.; Highfield, W.E.; Blessing, R.; Makino, T.; Shepard, C. Evaluating the effects of open space configurations in reducing flood damage along the Gulf of Mexico coast. Landsc. Urban Plan. 2017, 167, 225-231. [CrossRef]

48. Calil, J.; Newkirk, S. Aligning natural resource conservation, flood hazard mitigation, and social vulnerability remediation in Florida. J. Ocean Coast. Econ. 2017, 4. [CrossRef]

49. Tyler, J.; Sadiq, A.-A.; Noonan, D.S. A review of the community flood risk management literature in the USA: Lessons for improving community resilience to floods. Nat. Hazards 2019, 96, 1223-1248. [CrossRef]

50. Thieken, A.H.; Kienzler, S.; Kreibich, H.; Kuhlicke, C.; Kunz, M.; Muller, M.; Otto, A.; Petrow, T.; Pisi, S.; Schroeter, K. Review of the flood risk management system in Germany after the major flood in 2013. Ecol. Soc. 2016, 21. [CrossRef]

51. Veerbeek, W.; Ashley, R.M.; Zevenbergen, C.; Rijke, J.; Gersonius, B. Building adaptive capacity for flood proofing in urban areas through synergistic interventions. In Proceedings of the WSUD 2012-7th International Conference on Water Sensitive Urban Design: Building the Water Sensitive Community, Final Program and Abstract Book; Engineers Australia: Barton, Australia, 21 January 2012; ISBN 9780858258952. Available online: https://scholar.google.be/scholar?hl=ko\&as_sdt=0\%2C5\&q=Building+adaptive+capacity+ for+flood+proofing+in+urban+areas+through+synergistic+interventions.\&btnG $=$.

52. Michel-Kerjan, E.; Kunreuther, H. Redesigning flood insurance. Science 2011, 333, 408-409. [CrossRef]

53. Aerts, J.C.; Botzen, W. Climate change impacts on pricing long-term flood insurance: A comprehensive study for the Netherlands. Glob. Environ. Chang. 2011, 21, 1045-1060. [CrossRef]

54. Ermolieva, T.; Filatova, T.; Ermoliev, Y.; Obersteiner, M.; De Bruijn, K.; Jeuken, A. Flood catastrophe model for designing optimal flood insurance program: Estimating location-specific premiums in the netherlands. Risk Anal. 2016, 37, 82-98. [CrossRef]

55. Goniewicz, K.; Burkle, F.M. Analysis of the potential of IT system support in early warning systems: Mitigating flood risk in Poland. Prehospital Disaster Med. 2019, 34, 563-565. [CrossRef]

56. Kellens, W.; Terpstra, T.; De Maeyer, P. Perception and communication of flood risks: A systematic review of empirical research. Risk Anal. 2012, 33, 24-49. [CrossRef] [PubMed]

(C) 2020 by the authors. Licensee MDPI, Basel, Switzerland. This article is an open access article distributed under the terms and conditions of the Creative Commons Attribution (CC BY) license (http://creativecommons.org/licenses/by/4.0/). 